\title{
Recensión de la obra de Carmen Jover Ramírez: La protección de los whistleblowers en el seno de la relación jurídico laboral. Una mirada al panorama actual con perspectiva de futuro Laborum, Murcia, 2020
}

\author{
Cristina Sánchez-Rodas Navarro \\ Catedrática de Derecho del Trabajo y de la Seguridad Social \\ Universidad de Sevilla \\ csrodas@us.es @ 0000-0001-9780-7860
}

Recibido: 14.06.2020 | Aceptado: 14.06.2020

La autora aborda en esta obra un tema a la vez que novedoso casi desconocido en el ámbito jurídico laboral español. De hecho, pocas son a la fecha las obras doctrinales que han acometido su estudio. A ello debe añadirse que, si algo caracteriza a aquél, es el carácter pluridimensional de la figura que constituye el punto de partida de su estudio, el whistleblowing. Su repercusión mediática es innegable y de todos conocida, principalmente como consecuencia de los grandes escándalos financieros que han acompañado a la misma y que han llevado a traspasar las barreras de lo sensacionalista para reclamar, como no podía ser de otro modo, la respuesta del ordenamiento jurídico.

Desde el momento en el que el whistlewblowing hace mella en el ámbito de las relaciones laborales, la perspectiva jurídico laboral de la institución y de su principal protagonista, el trabajador, en su condición de whistleblower, marca la necesidad de poner en marcha el engranaje normativo para así hacer frente a la problemática que en dicha realidad pueda originarse. Y he ahí donde la autora se detiene, en una pequeña parcela de ese fenómeno mundial que tanto y tanto ha dado que hablar y que continuará dando y que recala en uno de los protagonistas más débiles, el trabajador, el cual, como en tantas y tantas otras ocasiones, necesita de nuevo de mecanismos de protección frente al empresario. En este caso, frente a las posibles represalias de las que pueda ser objeto tras cumplir con un deber moral y ético, en la mayoría de las ocasiones, y legal, en algunas otras.

Llama la autora la atención sobre la aún parca regulación de la cuestión en el ordenamiento jurídico laboral español frente a la existente a nivel internacional, tanto de países comunitarios como extra comunitarios. Ello exige, como no podía ser de otro modo, realizar el análisis de ese entorno para así poder aprender del mismo, en aras de su futura aplicabilidad en España. Así se justifica en el propio título de la obra, "una mirada actual 
con perspectiva de futuro". A juicio de la autora, se hace necesario conocer las distintas legislaciones que en la actualidad abordan la cuestión pues cuanto mayor sea el conocimiento de lo ajeno mejor será lo propio, pues se aprenderá de los errores de otros y se intentará salvar sus lagunas y carencias.

A este fin responde el análisis que la autora aborda en la parte II y III de la obra, destinadas respectivamente a la perspectiva internacional y comunitaria de la cuestión. La incidencia de la institución objeto de estudio en organismos internacionales lleva a estudiar necesariamente las mismas y a profundizar sobre su papel al respecto. Pero es necesario detenerse, y así lo hace la autora, en legislaciones concretas que ya han abordado el tratamiento de la materia, lo que se hace ofreciendo una visión de su plasmación normativa en los cinco continentes.

Pero desde lo más lejos, debemos ir aproximándonos a lo más cercano, siendo pues necesario, como no podía ser de otro modo, conocer el entorno de la Unión europea, tanto del propio compendio normativo del Derecho comunitario, por la incidencia que el mismo puede tener en España como Estado miembro que somos, así como de las legislaciones de aquellos países que ya han abordado la materia en sus propios ordenamientos.

El tratamiento que se hace es de gran actualidad desde el momento en el que se incorpora el estudio y análisis de la primera norma comunitaria en la materia y recientemente promulgada, cual es la Directiva (UE) 2019/1937 del Parlamento europeo y del Consejo, de 23 de octubre de 2019, relativa a la protección de las personas que informen sobre infracciones del Derecho de la Unión. Se realiza un recorrido por todo aquel articulado de la norma comunitaria que, directa o indirectamente, incide, a juicio de la autora, en el tema que recaba su atención, es decir, la protección del trabajador denunciante en el seno de la relación jurídico laboral, destacando el interés del estudio abordado pues el plazo de transposición de la misma está ahí y a ello tendrá España que responder.

Pero el interés por el entorno vuelve a exigir un estudio de algunos de los países de la Unión en los que la materia ya ha sido objeto de regulación y así lo hace la autora analizando las legislaciones de Francia, Italia, Luxemburgo, Irlanda y Hungría. No podemos dejar de mencionar el análisis de la normativa de Reino Unido efectuado por la autora, como normativa pionera en la materia y que, si bien, dados los acontecimientos que han Ilevado a su salida de la Unión, la autora redirige su estudio a los países externos a la Unión, ello no es óbice para que se resalte su consideración como referente en algunos de los otros ordenamientos jurídicos de la misma, como el irlandés, y su posible consideración por el ordenamiento español en la regulación que sobre la cuestión analizada llegue a efectuarse.

Esa mirada al panorama actual desde la perspectiva internacional y comunitaria tiene su reflejo en España en las partes IV y V de la obra, en las que la autora responde, respectivamente a lo ya anunciado en el título de la obra, a la mirada actual con perspectiva de futuro.

A la autora no le pasa desapercibido el hecho de que la materia analizada lo haya sido en el ordenamiento jurídico español desde perspectivas diferentes y no expre- 
samente referidas a la protección del trabajador denunciante pero que, sin embargo, constituyen un primer avance en la materia. La mirada al panorama actual exige de la autora bucear entre disposiciones normativas, convencionales, propuestas legislativas, códigos de conducta, códigos éticos de las empresas, protocolos frente al acoso etc. buscando todas aquellas medidas que, de una u otra forma, den respuesta a la protección del denunciante frente a posibles represalias del empleador. Ello, sin olvidar, el análisis del poder por excelencia con el que cuenta el empleador para sancionar al trabajador, el poder disciplinario. Estudio este último en el que la autora se detiene y del que llama la atención la diversidad de su contenido, entendemos que reclamado por el propio carácter plural que señalábamos y que le lleva a centrar su atención en instituciones tales como las llamadas "listas negras" así como a indagar sobre la protección jurisdiccional ofrecida al trabajador frente a las represalias empresariales. Igualmente, el estudio no se olvida de analizar la vía de reacción de nuestro ordenamiento jurídico laboral ante los incumplimientos del empresario, la potestad sancionadora de la Administración en el orden social. Materia en la que, como se pone de manifiesto, deberá el legislador prestar una especial atención.

Pero, como se decía al inicio, la autora realiza esa mirada al panorama actual con una perspectiva de futuro. Perspectiva esta que plasma en la parte $\vee$ de la obra ofreciendo interesantes propuestas de lege ferenda al legislador y que ponen de manifiesto la necesidad de que el ordenamiento jurídico español acompase su paso al ámbito internacional y comunitario.

La obra es así pues un revulsivo para el legislador español avisándolo de que tiene una tarea pendiente, de que está llamado a actuar y de que debe dar respuesta a una cuestión a la que muchos de los países ya se han enfrentado. No obstante, solo el tiempo dirá si el legislador español abordará dicha regulación o, continuará, como señala la autora viene sucediendo hasta ahora, pasando de soslayo sobre la misma. 